\title{
Cellulose Oxidation and the Use of Carboxyl Cellulose Metal Complexes in Heterogeneous Catalytic Systems to Promote Suzuki-Miyaura Coupling and C-O Bond Formation Reaction
}

\author{
Guilherme B. C. Martins, ${ }^{a}$ Marcelo R. dos Santos, ${ }^{a}$ Marcus V. R. Rodrigues, ${ }^{a}$ \\ Renata R. Sucupira, ${ }^{a}$ Luisa Meneghetti, ${ }^{a}$ Adriano L. Monteiro ${ }^{b}$ and Paulo A. Z. Suarez $z^{*, a}$ \\ aINCT-CATÁLISE, Laboratório de Materiais e Combustíveis, Instituto de Química, \\ Universidade de Brasília (IQ-UnB), Campus Universitário Darcy Ribeiro, \\ P.O. Box 4478, 70904-970 Brasília-DF, Brazil \\ ${ }^{b} I N C T$-CATÁLISE, Laboratório de Catálise Molecular, Instituto de Química, \\ Universidade Federal do Rio Grande do Sul (IQ-UFRGS), 90040-060 Porto Alegre-RS, Brazil
}

\begin{abstract}
This work shows the modification of microcrystalline cellulose by the selective oxidation of primary hydroxyl groups to carboxylate groups by a 2,2,6,6-tetramethylpiperidine-1-oxyl radical (TEMPO)-mediated system and its application as a heterogeneous ligand by ionic exchange with catalytic metals ions such as palladium, nickel and copper. Afterwards is described the application of the synthesized material as catalyst in coupling reactions such as Suzuki-Miyaura coupling and $\mathrm{C}-\mathrm{O}$ bond formation reaction in different conditions, which are of great importance for the synthesis of drugs, natural products and new materials such as dendrimers, liquid crystals and polymers with magnetic and optical properties. The carboxyl cellulose matrix shows to have superior catalytic results as a ligand for all coupling reactions. Can be also highlighted the affinity of the carboxyl cellulose ligand in polar solvents such as water and alcohols and its application in mild conditions.
\end{abstract}

Keywords: cellulose modification, TEMPO oxidation, metal ligand, coupling reactions, carboxyl cellulose

\section{Introduction}

Brazil is the fourth cellulose producer in the world and in 2014 the production was 16.46 million tons $(64 \%$ was exported). ${ }^{1}$ However, most of the cellulose is used for paper and other low cost products. Thus, it is important to develop products by modifying cellulose in order to aggregate value in such important feedstock. Indeed, some derivatives have been developed and are actually manufactured on an industrial scale and applied in coatings, laminates, optical films, building materials, pharmaceuticals, foodstuffs and cosmetics. $^{2}$

On the other hand, the main challenge of modern catalysis is to achieve environment-friendly processes, using sustainable resources and very active catalysts. ${ }^{3-6}$ In this regard, biopolymers are attractive for use combined with transition metal catalysts for further applications in organic synthesis, fine chemical and flow reactors, ${ }^{7-14}$ and

*e-mail: psuarez@unb.br cellulose may have a great potential of use in heterogeneous catalysis.

The formation of bonds catalyzed by transition metals is considered one of the most important processes in synthetic chemistry, helping to build complex molecules structures from simple precursors. ${ }^{15}$ Cross-coupling reactions are one of the most efficient methods for achieving this goal, performing a reaction between an organometallic compound and organic electrophile mediated by palladium, nickel or copper complexes. Some important reactions in this context, which are widely applied in organic synthesis, can be mentioned, such as the Suzuki-Miyaura, Stille, Negishi, Sonogashira, Mizoroki-Heck and BuchwaldHartwig couplings. ${ }^{16-18}$

Because of the characteristic insolubility of cellulose and some of its derivatives, a plenty of studies has been carried using those material as heterogeneous support in SuzukiMiyaura coupling reactions. Palladium nanoparticles have been supported on cellulose without modification and applied to Suzuki-Miyaura couplings. ${ }^{8}$ The modification 
of cellulose to anchoring palladium species for catalytic application in Suzuki-Miyaura reactions is also reported in different ways, such as cellulose-aluminum oxide composite modified with organic groups, ${ }^{9}$ modified carboxymethyl cellulose ${ }^{19}$ and functionalized cellulose. ${ }^{20}$

In the last decade, the selective oxidation of the primary alcohols of carbohydrates structure into carboxylates using $n$-oxil-2,2,6,6-tetramethylpiperidine (TEMPO) catalytic oxidation has been reported. ${ }^{21-24}$ This process has also been applied to cellulose leading to new cellulose derivative. ${ }^{25-27}$ The formation of carboxyl sites in cellulose structure permits the directly coordination of metal ions in its structure, dispensing the use of anchoring molecules for that purpose. The carboxyl cellulose by TEMPO mediated oxidation may be used, not as a support for metals with catalytic activity, but as a ligand to be applied in organic reactions, opening new possibilities of use and application for cellulose.

Recently, the management of Suzuki-Miyaura reactions under mild conditions using water preferentially as solvent has been studied using sulfate silica and phosphine palladium-platinum bi-nuclear complexes, ${ }^{28,29}$ mainly to reduce the cost and also making an environment-friendly reaction. Due to the insolubility in water of cellulose materials, even carboxyl cellulose, we believe that it is possible to use them to afford water based multi-phase systems, substituting organic solvents which are more dangerous, expensive and polluting. Other advantages of cellulose based materials are their low cost, their reusability and their biodegradability, attending to green and sustainable principles widespread in chemistry today. ${ }^{30,31}$

Therefore, we envisage in this work the synthesis of new catalysts based on palladium, nickel and copper complexed with carboxyl cellulose, for application as catalysts in C-C and $\mathrm{C}-\mathrm{O}$ bond formation, in order to achieve an efficient and environmentally friendly catalytic system, according to the principles of green and sustainable chemistry.

\section{Experimental}

\section{Reagents}

Commercial microcrystalline cellulose from Merck (Art.2331), n-oxil-2,2,6,6-tetramethylpiperidine (TEMPO), sodium bromide, a $12 \%$ sodium hypochlorite solution, bromobenzene, bromoanisole, arylboronic acids, potassium carbonate $\left(\mathrm{K}_{2} \mathrm{CO}_{3}\right)$, palladium acetate (II) $\left(\mathrm{Pd}(\mathrm{OAc})_{2}\right)$, nickel acetate (II) $\left(\mathrm{Ni}(\mathrm{OAc})_{2}\right)$, copper acetate (II) $\left(\mathrm{Cu}(\mathrm{OAc})_{2}\right)$ and other solvents and reagents were analytical grade and used as purchased from commercial sources, without further purification.

\section{Apparatus}

Nuclear magnetic resonance spectrums of hydrogen $\left({ }^{1} \mathrm{H}\right.$ NMR) and carbon $\left({ }^{13} \mathrm{C}\right.$ NMR) were obtained on a Varian Gemini $300 \mathrm{MHz}$ equipment. Chemical shifts $(\delta)$ were expressed in parts per million (ppm) and referenced by the sign of TMS and chloroform. Infrared spectra were obtained in a Shimadzu IR PRESTIGE-21 equipment, using an ATR (attenuated total reflectance) cell analysing the range from 600 to $4000 \mathrm{~cm}^{-1}$. Gas chromatography (GC) analysis was performed using a Shimadzu GC-2104 equipment, using a shimpack semi-capillary column (5\% PhMe silicone, $30 \mathrm{~m} \times 0.25 \mathrm{~mm} \times 0.25 \mu \mathrm{m})$. The analysis was performed by GC using the following standard condition: $\mathrm{T}$ (injector $)=250^{\circ} \mathrm{C} ; \mathrm{T}(\mathrm{FID}$ detector $)=250^{\circ} \mathrm{C}$; carrier gas = nitrogen; oven temperature program: $100{ }^{\circ} \mathrm{C}$ for $1 \mathrm{~min}$, then heated to $250{ }^{\circ} \mathrm{C}$ using a heating rate of $20{ }^{\circ} \mathrm{C} \mathrm{min}^{-1}$, and kept at this temperature for $7 \mathrm{~min}$. Thermogravimetric analysis (TGA) was performed using a Shimadzu TG-60 equipment. During the analysis, the system was purged with $\mathrm{N}_{2}$ flow at a rate of $50 \mathrm{~mL} \mathrm{~min}^{-1}$. The average mass weighed was $10 \mathrm{mg}$ and the measurements were carried out between 25 and $450{ }^{\circ} \mathrm{C}$, with a heating rate of $20^{\circ} \mathrm{C} \mathrm{min}^{-1}$. ICP OES (inductively coupled plasma optical emission spectroscopy) analysis was performed using an iCAP 6000 series equipment from Thermo Scientific. The samples $(50 \mathrm{mg}$ ) were previously digested in sulfuric acid $(50 \mathrm{~mL})$ at $200{ }^{\circ} \mathrm{C}$ for $1 \mathrm{~h}$. The energy dispersive $\mathrm{X}$-ray fluorescence spectrometry (EDX) was carried out in an EDX-720 equipment from Shimadzu under vacuum conditions using a collimator of $5 \mathrm{~mm}$. The isotherms of adsorption and desorption of $\mathrm{N}_{2}$ were obtained in a QuantaChrome Nova 2200e equipment, and the surface area was calculated by BET (Brunauer-Emmett-Teller) method.

\section{TEMPO-mediated oxidation}

The microcrystalline cellulose was modified by TEMPO-mediated oxidation converting the primary alcohol from cellulose in a carboxylate group, according to the standard procedure described below: the microcrystalline cellulose $(1 \mathrm{~g})$ was suspended in a water solution $(100 \mathrm{~mL})$ containing TEMPO (0.016 g, $0.1 \mathrm{mmol})$ and sodium bromide $(0.1 \mathrm{~g}, 1 \mathrm{mmol})$. The $12 \% \mathrm{NaClO}$ solution was adjusted to $\mathrm{pH} 10$ by the addition of $0.1 \mathrm{M} \mathrm{HCl}$ solution. The TEMPO-mediated oxidation was started by adding of the $\mathrm{NaClO}$ solution $(2.86 \mathrm{~mL}, 5.0 \mathrm{mmol})$ and was kept at room temperature with stirring for $3 \mathrm{~h}$. The $\mathrm{pH}$ was kept at 10 by adding $0.5 \mathrm{M} \mathrm{NaOH}$ solution using a $\mathrm{pH}$ stat until no consumption of $\mathrm{NaOH}$ was observed. The reaction mixture was centrifuged and the obtained solid was washed with 
water and dried under reduced pressure in room temperature $\left(24{ }^{\circ} \mathrm{C}\right)$ during $12 \mathrm{~h}$ until no variation in the mass was observed, leading to the sodium carboxyl cellulose $(\mathrm{NaCC})$.

\section{Acidification of the sodium carboxyl cellulose}

The acidification was carried out by adding $20 \mathrm{~mL}$ of $3 \mathrm{M}$ solution $\mathrm{HCl}$ solution prepared with Milli-Q water in $1 \mathrm{~g}$ of NaCC obtained previously. The mixture was left under stirring during $3 \mathrm{~h}$. Thereafter the mixture was filtered and washed with the $\mathrm{HCl}$ solution, followed by Milli-Q water and then by ethanol p.a. The acidified product was called HCC.

\section{Preparation of metal carboxyl cellulose catalysts}

The metal carboxyl cellulose (MCC) catalysts were prepared by treating $1 \mathrm{mmol}$ of corresponding metal acetate $\left(\mathrm{Pd}(\mathrm{OAc})_{2}, \mathrm{Ni}(\mathrm{OAc})_{2}\right.$ and $\left.\mathrm{Cu}(\mathrm{OAc})_{2}\right)$ with $4 \mathrm{mmol}$ of the $\mathrm{NaCC}$ in a mixture of methanol/acetonitrile $1: 1(4 \mathrm{~mL})$. The mixture was kept under stirring for $2 \mathrm{~h}$ at $60{ }^{\circ} \mathrm{C}$. After this period, the solvent was removed under reduced pressure and therefore washed with water and filtered. The products, labeled generally as metal carboxyl cellulose (MCC), were also labeled according to the metal acetate used in the ionic exchange, described as palladium carboxyl cellulose (PdCC), nickel carboxyl cellulose (NiCC) and copper carboxyl cellulose $(\mathrm{CuCC})$.

\section{General procedure for Suzuki-Miyaura coupling}

In a sealed Schlenk tube containing $3 \mathrm{~mL}$ of solvent, base $(1.5 \mathrm{mmol})$, arylboronic acid $(0.7 \mathrm{mmol})$, catalyst $(0.5 \%)$ and aryl halide $(0.5 \mathrm{mmol})$ were added. The reaction was stirred under argon atmosphere at the programmed time and temperature. The organic phase was extracted with $10 \mathrm{~mL}$ of dichloromethane and an aliquot was removed for $\mathrm{GC}$ analysis.

A series of reactions were performed using different temperature and solvents, in order to analyze the behavior of the new catalysts and to find an optimum condition to form the product of the coupling between the substrates.
Also PdCC and NiCC were compared with their respective standard catalyst acetate metal, to observe the catalytic activity of the synthesized materials. The reactions of cross coupling involving PdCC and NiCC were performed as shown in Scheme 1.

\section{4-OMe-Biphenyl}

${ }^{1} \mathrm{H} \mathrm{NMR}\left(300 \mathrm{MHz}, \mathrm{CDCl}_{3}\right) \delta 7.54\left(\mathrm{t}, 4 \mathrm{H},{ }^{3} J_{\mathrm{HH}}=9.0 \mathrm{~Hz}\right)$, $7.41\left(\mathrm{t}, 2 \mathrm{H},{ }^{3} J_{\mathrm{HH}}=7.8 \mathrm{~Hz}\right), 7.29(\mathrm{~m}, 1 \mathrm{H}), 6.97(\mathrm{~d}, 2 \mathrm{H}$, ${ }^{3} J_{\mathrm{HH}}=8.7 \mathrm{~Hz}$ ), $3.84(\mathrm{~s}, 3 \mathrm{H}) ;{ }^{13} \mathrm{C}$-APT (attached proton test) NMR (75 MHz, $\left.\mathrm{CDCl}_{3}\right) \delta 159.1,140.8,133.6,128.6$, 128.1, 126.7, 126.6, 114.1, 55.3.

\section{4-Me-Biphenyl}

${ }^{1} \mathrm{H} \mathrm{NMR}\left(300 \mathrm{MHz}, \mathrm{CDCl}_{3}\right) \delta 7.55\left(\mathrm{~d}, 2 \mathrm{H},{ }^{3} \mathrm{~J}_{\mathrm{HH}}=6.9 \mathrm{~Hz}\right)$, $7.46\left(\mathrm{~d}, 2 \mathrm{H},{ }^{3} J_{\mathrm{HH}}=8.1 \mathrm{~Hz}\right), 7.39\left(\mathrm{t}, 2 \mathrm{H},{ }^{3} J_{\mathrm{HH}}=7.8 \mathrm{~Hz}\right)$, $7.28(\mathrm{~m}, 1 \mathrm{H}), 7.21\left(\mathrm{~d}, 2 \mathrm{H},{ }^{3} J_{\mathrm{HH}}=7.8 \mathrm{~Hz}\right), 2.36(\mathrm{~s}, 3 \mathrm{H})$; ${ }^{13} \mathrm{C}$-APT NMR (75 MHz, $\left.\mathrm{CDCl}_{3}\right) \delta 141.0,138.3,136.9$, 129.4, 128.6, 126.9, 21.0.

\section{4-Ac-Biphenyl}

${ }^{1} \mathrm{H} \mathrm{NMR}\left(300 \mathrm{MHz}, \mathrm{CDCl}_{3}\right) \delta 8.03\left(\mathrm{~d}, 2 \mathrm{H},{ }^{3} \mathrm{~J}_{\mathrm{HH}}=13.8\right.$ and $8.4 \mathrm{~Hz}), 7.81\left(\mathrm{~d}, 2 \mathrm{H},{ }^{3} \mathrm{~J}_{\mathrm{HH}}=8.7 \mathrm{~Hz}\right), 7.64(\mathrm{~m}, 3 \mathrm{H}), 7.45$ (m, 2H), 2.60 (s, 3H); ${ }^{13} \mathrm{C}$-APT NMR (75 MHz, $\mathrm{CDCl}_{3}$ ) $\delta$ 197.7, 145.8, 139.8, 135.7, 131.8, 129.8, 128.9, 128.8, $128.1,127.2,127.1,26.6$.

\section{General procedure for $\mathrm{C}-\mathrm{O}$ bond formation reaction}

In a sealed Schlenk tube containing $1 \mathrm{~mL}$ of alcohol, $\mathrm{Cs}_{2} \mathrm{CO}_{3}(2.0 \mathrm{mmol})$, bromobenzene $(1.0 \mathrm{mmol})$, catalyst $(1.0 \%)$ and phenantroline $(5.0 \mathrm{~mol} \%)$ were added. The reaction was stirred under argon atmosphere for $24 \mathrm{~h}$ at $130^{\circ} \mathrm{C}$ and an aliquot was removed for GC analysis.

$\mathrm{CuCC}$ was used for the coupling reaction involving heteroatoms, in which the main reagent is used also as a solvent during the reaction. ${ }^{32}$ The reaction that followed was similar to those described in the literature. ${ }^{33,34}$ Also a comparison with standard catalyst cupper acetate catalyst was performed to observe the catalytic activity of the $\mathrm{CuCC}$. The reaction was performed according to Scheme 2.

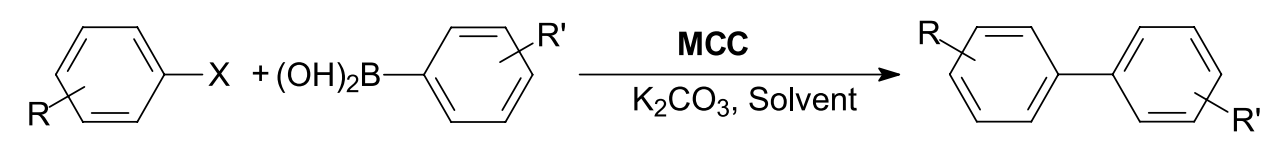

Scheme 1. The Suzuki coupling reaction catalyzed by MCC.

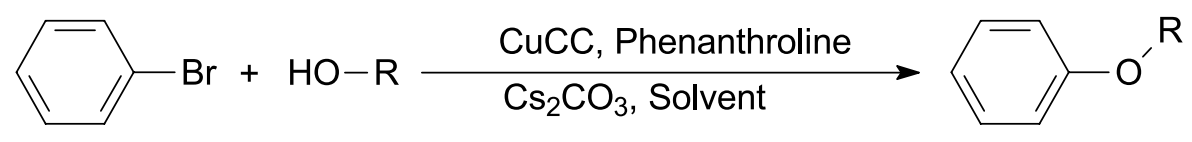

Scheme 2. $\mathrm{C}-\mathrm{O}$ bond formation reaction promoted by $\mathrm{CuCC}$. 
1-OPe-Phenyl

${ }^{1} \mathrm{H}$ NMR (300 MHz, $\left.\mathrm{CDCl}_{3}\right) \delta 7.42(\mathrm{~m}, 3 \mathrm{H}), 6.98(\mathrm{~d}$, $\left.2 \mathrm{H},{ }^{3} J_{\mathrm{HH}}=8.7 \mathrm{~Hz}\right), 4.0\left(\mathrm{t}, 2 \mathrm{H},{ }^{3} J_{\mathrm{HH}}=6.5 \mathrm{~Hz}\right), 1.80(\mathrm{~m}, 2 \mathrm{H})$, $1.53(\mathrm{~m}, 4 \mathrm{H}), 1.00\left(\mathrm{t}, 3 \mathrm{H},{ }^{3} J_{\mathrm{HH}}=7.3 \mathrm{~Hz}\right) ;{ }^{13} \mathrm{C}$-APT NMR $\left(75 \mathrm{MHz}, \mathrm{CDCl}_{3}\right) \delta 158.7,140.8,126.5,115.1,67.7,31.3$, 20.1, 19.2, 13.8.

\section{Results and Discussion}

\section{Cellulose oxidation characterization}

During the TEMPO-mediated oxidation reaction, no solubility of the cellulose was observed. At the end of the reaction a light brown solid was obtained, contrasting with the white color of its precursor. The solubility of the $\mathrm{NaCC}$ material was evaluated in water, methanol, ketone, tetrahydrofuran, dimethylsulfoxide, dichloromethane, ethyl acetate, toluene and hexane. None of the solvents tested were able to solubilize $\mathrm{NaCC}$, showing that the material has solubility similar to microcrystalline cellulose. Indeed, after filtering and drying under vacuum, it was observed no significant variation in the mass of the solid, suggesting its completely insolubility in the evaluated solvents.

The modified functional groups in the microcrystalline cellulose were evaluated by attenuated total reflectance infrared spectroscopy analysis (ATR-IR). Comparing the ATR-IR spectra of microcrystalline cellulose and $\mathrm{NaCC}$ presented in Figure 1 it can be observed the appearance of an intense absorption band at $1605 \mathrm{~cm}^{-1}$ after the treatment with TEMPO, corresponding to the appearance of carbonyl stretching frequency for carboxyl groups, which were absent in microcrystalline cellulose spectra. The appearance of carboxylate bands in the FTIR spectra of $\mathrm{NaCC}$, confirms the oxidation of the microcrystalline cellulose alcohols groups into carboxilate. ${ }^{35}$ According to the ATR-IR data, TEMPO-mediated oxidation was successfully applied for the oxidation of the primary hydroxyl groups in the carboxyl groups, as related elsewhere. ${ }^{36}$ It becomes also clear from Figure 1 that the other regions in the ATR-IR spectra of microcrystalline cellulose and $\mathrm{NaCC}$ had no other significantly change, especially in the bands related to 1,4-glycosides bonds $\left(1200-1000 \mathrm{~cm}^{-1}\right)$. This result suggests that no other changes in the cellulose structure were achieved during TEMPO oxidation, allowing us to assume that the modified cellulose chain is almost the same of the starting commercial microcrystalline cellulose. This result was partially expected as far as it is largely known that to undergo cellulose hydrolysis and, thus, its depolymerization, more drastic conditions may be used. ${ }^{37-39}$ However, further studies should be done to prove no other changes in the cellulose structure took place.
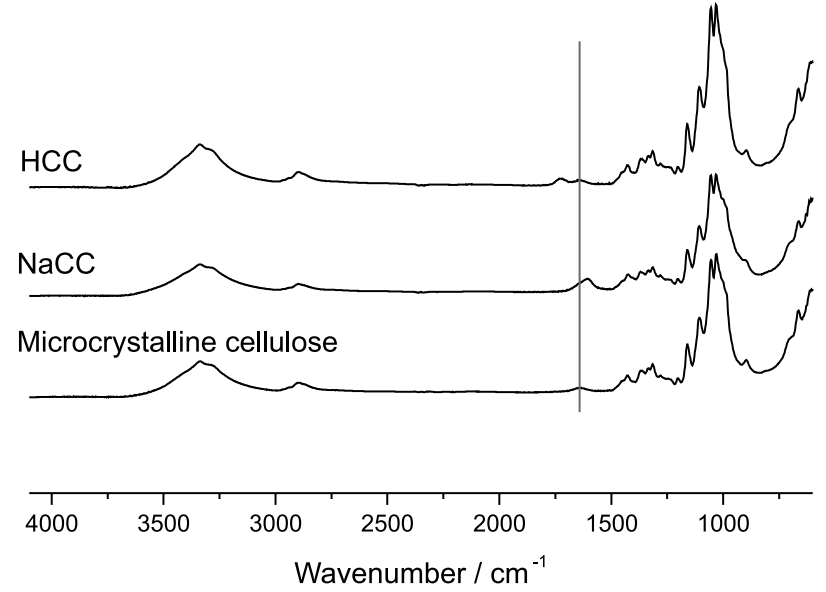

Figure 1. ATR-IR of microcrystalline cellulose before and after TEMPOmediated oxidation $(\mathrm{NaCC})$, and the acidification of the TEMPO modified product (HCC).

Comparing the ATR-IR spectra of $\mathrm{NaCC}$ and $\mathrm{HCC}$ in Figure 1 it can be seen the disappearance of the band in $1605 \mathrm{~cm}^{-1}$, related to $\mathrm{C}=\mathrm{O}$ stretching of sodium carboxyl group, and the appearance of a new band in $1725 \mathrm{~cm}^{-1}$, related to $\mathrm{C}=\mathrm{O}$ stretching of carboxylic acids. This observation evidences the complete acidification of $\mathrm{NaCC}$ material. Again, no other significantly modification can be seen in ATR-IR spectra in both obtained materials.

To quantify the conversion of alcohols into carboxyl groups, $\mathrm{HCC}$ was titrated using a standard $\mathrm{KOH}$ solution. Comparing the result with theoretical total amount of hydroxyl groups in microcrystalline cellulose it was determined a conversion of $10 \%$. This low yield may be due to most of the hydroxyl groups inside the cellulose fibers and not accessible to react.

The isotherm of the synthetized material can be seen in Figure 2. According to this analysis, $\mathrm{NaCC}$ has a lower capacity as adsorbent when compared to microcrystalline cellulose. The calculated superficial area of the materials by BET method is 17.587 and $15.200 \mathrm{~m}^{2} \mathrm{~g}^{-1}$ for microcrystalline cellulose and $\mathrm{NaCC}$, respectively, showing a reduction of the superficial area of proximally $14 \%$ after oxidation. The isotherm of $\mathrm{NaCC}$, which is similar to the microcrystalline cellulose isotherm, adjust in the isotherm type $\mathrm{III},{ }^{40}$ where the adsorbate interact more with an adsorbed layer than with the adsorbate surface.

\section{MCC complexes characterization}

$\mathrm{NaCC}$ was treated with nickel, palladium and copper salts. New solids were obtained after the treatment, each one with characteristic colors. The NiCC had a pale green color; PdCC has a black color; and $\mathrm{CuCC}$ a light green color. Their solubility was evaluated with the same 


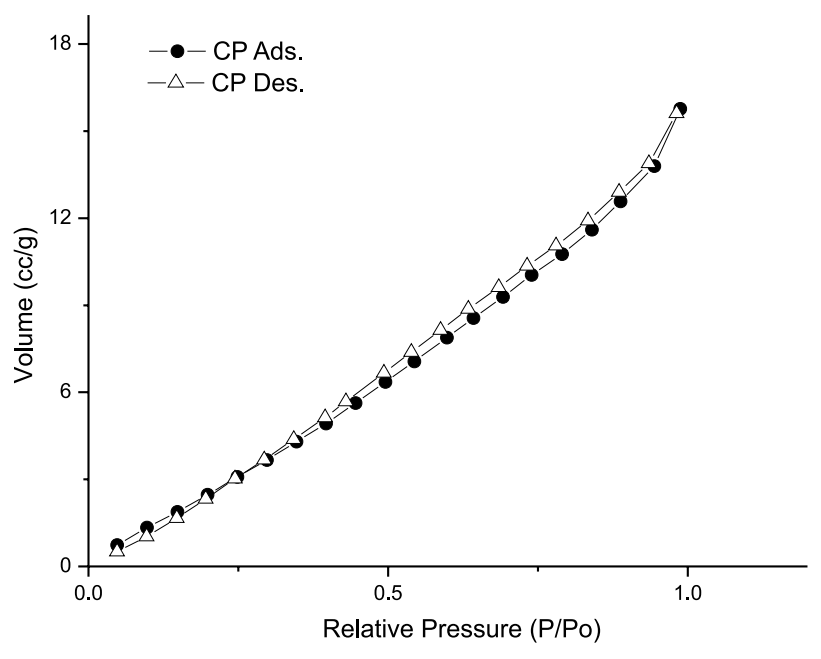

Figure 2. Isotherms of the $\mathrm{NaCC}$ material obtained using $\mathrm{N}_{2}$ gas adsorption/desorption.

solvents tested in $\mathrm{NaCC}$ and the same insolubility of the materials were observed. It is worth mentioning that the recovered solvents were analyzed by ICP and was observed no detectable metal content, suggesting no significant leaching of metals from NiCC, PdCC and CuCC. This behavior indicates that the metal exchange does not affect the insolubility of the modified celluloses, allowing their application as heterogeneous catalyst.

To verify the complexation of the metal cations with the carboxyl groups, an ATR-IR analysis was performed (see Figure 3 ). The metal bound is confirmed by the enlargement and delocation of the band related to the carboxylate group. Indeed, the infrared data shows the delocation of the $\mathrm{C}=\mathrm{O}$ band, indicating the cationic change in the materials. The maximium wave number of $\mathrm{C}=\mathrm{O}$ band shifted from $1605 \mathrm{~cm}^{-1}$ in the $\mathrm{NaCC}$ to $1606,1596,1625 \mathrm{~cm}^{-1}$ for PdCC, $\mathrm{NiCC}$ and $\mathrm{CuCC}$, respectively.

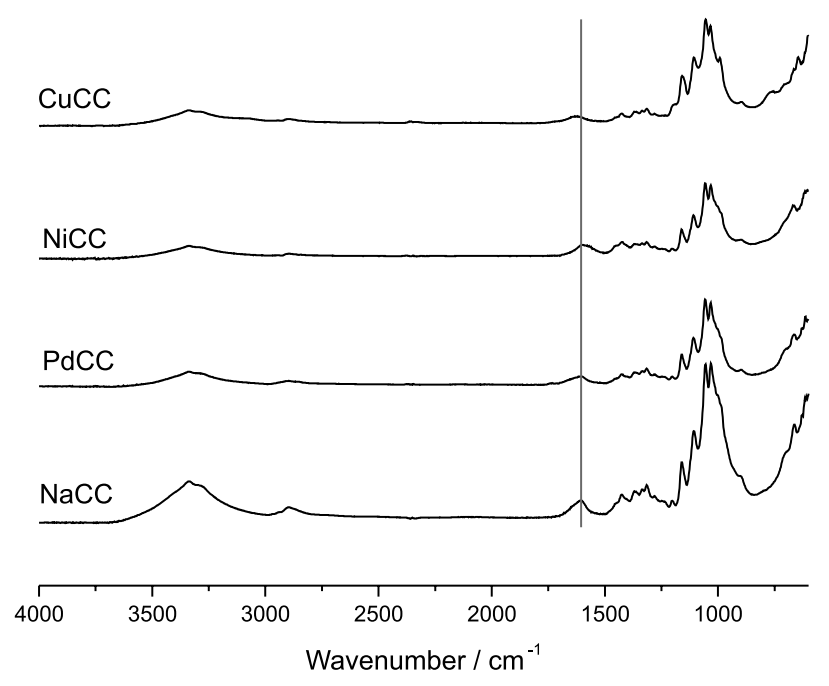

Figure 3. Infrared spectra of the $\mathrm{NaCC}$ and $\mathrm{MCC}$ materials.
The metal cation exchange was determined by EDX as the proportion of sodium/metal $(\mathrm{Na} / \mathrm{M})$. The materials treated with palladium, nickel and copper showed $\mathrm{Na} / \mathrm{M}$ ratio of 5.8, 1.0 and 1.2, respectively. Thus, the cationic exchange yield was determined as 15,50 and $45 \%$ for $\mathrm{PdCC}, \mathrm{NiCC}$ and $\mathrm{CuCC}$, respectively. Also, ICP OES analyses were performed to determine the total amount of metal after the ionic exchange. The concentrations obtained were 96, 50, and $60 \mathrm{mg} \mathrm{kg}^{-1}$ for $\mathrm{PdCC}, \mathrm{NiCC}$ and $\mathrm{CuCC}$, respectively. Which means a concentration of 0.000902 , 0.000851 , and $0.000944 \mathrm{mmol} \mathrm{g}^{-1}$ for PdCC, NiCC and $\mathrm{CuCC}$, respectively. The variation in the EDX and ICP data can be related to the molar mass of the cations and also that EDX analysis occur only in the surface of the material, however the molar amount of cations are similar in the synthetized materials.

TGA analysis (Figure 4) indicates that the $\mathrm{NaCC}$ and its metal complexes decompose after $200{ }^{\circ} \mathrm{C}$, remaining relatively stable before they reach this temperature. It was possible to observe a small loss of mass, averaging $10 \%$, before reaching $200{ }^{\circ} \mathrm{C}$, which may be related to the loss of light compounds, such as water, adsorbed in the cellulose structure. Between 200 and $325^{\circ} \mathrm{C}$ a considerable mass loss is observed, probably indicating a thermal decomposition of the ligand structure.

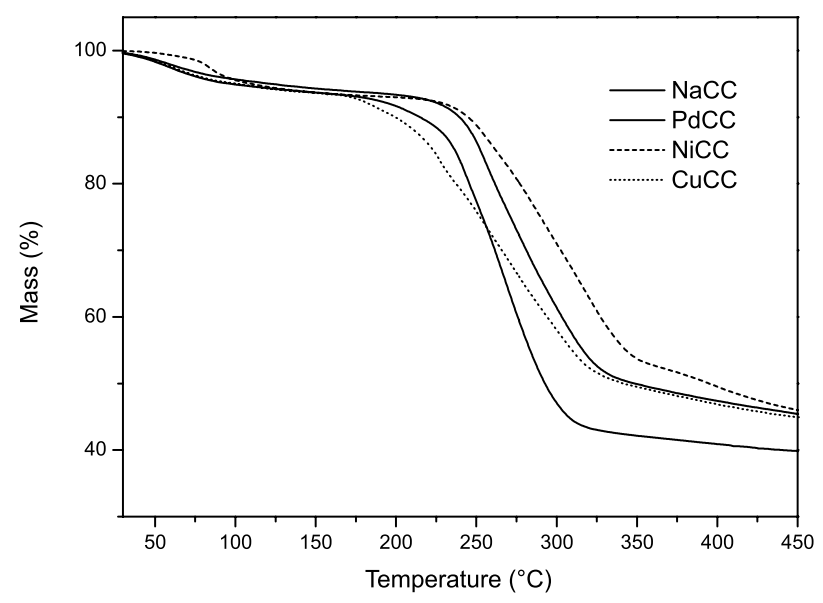

Figure 4. Thermogravimetrical analysis of the $\mathrm{NaCC}$ and $\mathrm{MCC}$ materials.

\section{$\mathrm{Pd}-\mathrm{CC}$ and $\mathrm{Ni}-\mathrm{CC}$ cross coupling reactions}

The application of the obtained catalysts in crosscoupling reactions was started using the palladium carboxyl cellulose (PdCC) in the Suzuki-Miyaura reaction for the construction of biaryl units. ${ }^{4-43}$ According to the literature, this reaction has the advantage of the flexibility of arylboronic acids with different functional groups, also acting with good stability against water, oxygen and heat. ${ }^{41}$ The main results are shown in Table 1. 
Table 1. Values of variation parameters in Suzuki coupling reactions catalyzed by MCC

\begin{tabular}{|c|c|c|c|c|c|}
\hline entry & Metal & Solvent & Temperature $/{ }^{\circ} \mathrm{C}$ & Yielde / \% & $\mathrm{HC}$ yield $^{\mathrm{f}} / \%$ \\
\hline $1^{\mathrm{a}}$ & $\mathrm{Pd}$ & $\mathrm{H}_{2} \mathrm{O} / \mathrm{DMF}^{\mathrm{d}}$ & 80 & 100 & $<1$ \\
\hline $2^{a}$ & $\mathrm{Pd}$ & DMF & 80 & 20 & $<1$ \\
\hline $3^{\mathrm{a}}$ & $\mathrm{Pd}$ & $\mathrm{MeOH}$ & 80 & 94 & $<1$ \\
\hline $4^{a}$ & $\mathrm{Pd}$ & toluene & 80 & 25 & $<1$ \\
\hline $5^{\mathrm{a}}$ & $\mathrm{Pd}$ & THF & 80 & 18 & $<1$ \\
\hline $6^{\mathrm{a}}$ & $\mathrm{Pd}$ & $\mathrm{H}_{2} \mathrm{O}$ & 80 & 25 & $<1$ \\
\hline $7^{\mathrm{a}}$ & $\mathrm{Pd}$ & $\mathrm{H}_{2} \mathrm{O} / \mathrm{MeOH}^{\mathrm{d}}$ & 80 & 93 & $<1$ \\
\hline $8^{\mathrm{a}, \mathrm{c}}$ & $\mathrm{Pd}$ & $\mathrm{MeOH}$ & 80 & 100 & 2 \\
\hline $9^{\mathrm{a}, \mathrm{c}}$ & $\mathrm{Pd}$ & DMF & 80 & 76 & 2 \\
\hline $10^{\mathrm{a}}$ & $\mathrm{Pd}$ & $\mathrm{H}_{2} \mathrm{O} / \mathrm{DMF}^{\mathrm{d}}$ & 30 & 92 & $<1$ \\
\hline $11^{\mathrm{a}}$ & $\mathrm{Pd}$ & $\mathrm{MeOH}$ & 30 & 27 & $<1$ \\
\hline $12^{\mathrm{a}}$ & $\mathrm{Pd}$ & $\mathrm{H}_{2} \mathrm{O}$ & 30 & 11 & $<1$ \\
\hline $13^{\mathrm{b}}$ & $\mathrm{Ni}$ & dioxane & 130 & 5 & $<1$ \\
\hline $14^{\mathrm{b}}$ & $\mathrm{Ni}$ & toluene & 130 & 40 & 5 \\
\hline $15^{\mathrm{b}, \mathrm{g}}$ & $\mathrm{Ni}$ & dioxane & 130 & $<1$ & traces \\
\hline $16^{\mathrm{b}, \mathrm{g}}$ & $\mathrm{Ni}$ & toluene & 130 & 2 & 1 \\
\hline
\end{tabular}

Reaction conditions: $0.5 \mathrm{mmol}$ of bromobenzene, $0.7 \mathrm{mmol}$ of 4-methoxyphenylboronic acid, $1.5 \mathrm{mmol}$ of $\mathrm{K}_{2} \mathrm{CO}_{3}, 0.5 \%$ of catalyst, $3 \mathrm{~mL}$ of solvent, $1 \mathrm{~h}$ of reaction under argon atmosphere; ${ }^{b}$ reaction conditions: $1.0 \mathrm{mmol}$ of 4-bromoanisole, $1.2 \mathrm{mmol}$ of phenylboronic acid, $2.0 \mathrm{mmol}^{\circ} \mathrm{K}_{2} \mathrm{CO}_{3}, 1.0 \%$ of catalyst, $4.0 \mathrm{~mol} \%$ of triphenylphosfine, $3 \mathrm{~mL}$ of solvent, at $130{ }^{\circ} \mathrm{C}, 24 \mathrm{~h}$ of reaction under argon atmosphere; ${ }^{\mathrm{c} u s i n g} \mathrm{Pd}(\mathrm{OAc})_{2}$; ${ }^{\mathrm{d}}$ proportion between the solvents of 1:1; ${ }^{\mathrm{e} y i e l d}$ of GC based on aryl halide; fyield of homocoupling of arylboronic acid; ${ }^{\mathrm{g}}$ using $\mathrm{Ni}(\mathrm{OAc})_{2}$.

First, we investigated the cross-coupling of bromobenzene with 4-methoxyphenylboronic acid at $80{ }^{\circ} \mathrm{C}$ and $1 \mathrm{~h}$ of reaction, and high conversion on the cross-coupling product was obtained using a mixture of $\mathrm{H}_{2} \mathrm{O} / \mathrm{DMF}$ or methanol as solvent (Table 1, entries 1 and 3). However, when using DMF or $\mathrm{H}_{2} \mathrm{O}$ separately, low conversion was observed (Table 1, entries 2 and 6). Low yields were observed when less polar solvents such as THF or toluene were used (Table 1, entries 4 and 5). When the reaction was carried out with a mixture $\mathrm{H}_{2} \mathrm{O}$ /methanol (1:1), a higher yield was also obtained (Table 1, entry 7). These results indicate that a suitable polarity is necessary to allow the interaction between the substrate and the catalyst. For comparison, $\mathrm{Pd}(\mathrm{OAc})_{2}$ was also employed as a catalyst and gave very good yields but also a higher content of homocoupling product (Table 1, entries 8 and 9). Then we tested the catalyst at low temperature (Table 1, entries 10-12). We were delighted to see that, when using a mixture of $\mathrm{H}_{2} \mathrm{O} / \mathrm{DMF}$ as solvent, $\mathrm{PdCC}$ is able to perform Suzuki cross-coupling at low temperature $\left(30^{\circ} \mathrm{C}\right)$ and in a short time (1 h).

To evaluate the scope and limitations of this procedure, the reactions of some representative aryl halides and arylboronic acids were examined using $\mathrm{PdCC}$ in $\mathrm{H}_{2} \mathrm{O} / \mathrm{DMF}$ at $30{ }^{\circ} \mathrm{C}$ for $1 \mathrm{~h}$ (Table 2). Iodobenzene and both the electron-rich 4-bromonisole and the electron-poor 4-bromoacetophenone are efficiently coupled in the presence of PdCC to provide the corresponding biaryl products in quantitative yield (Table 2, entries 1, 3 and 4). Very low yield was observed for the 4-chloroanisole (Table 2, entry 2), an extremely deactivated substrate that normally requires the addition of special ligands to be coupled, as related in literature. ${ }^{44} \mathrm{We}$ also evaluated the steric effect, first using $p$-, $m$ - and $o$-bromotoluene. At $30{ }^{\circ} \mathrm{C}, o$-bromotoluene gave a lower yield $(60 \%$, Table 2 , entry 7). However, $o$-bromotoluene can be quantitatively coupled by raising the temperature to $80{ }^{\circ} \mathrm{C}$ (Table 2, entry 8 ). The system was sensitive to steric effects. Indeed, steric-demanding combinations involving two or three substitutions leads to low yields (Table 2, entries 9-11). Again, these are very challenging substrates for the Suzuki cross-coupling, where only the addition of a very specific ligand can effectively promote the coupling reaction. ${ }^{45}$

Nickel carboxyl cellulose (NiCC) was also evaluated for the Suzuki coupling reactions. ${ }^{46}$ First, a test was performed for $6 \mathrm{~h}$ in the absence of ligands; however, no coupling product was formed. Based on this preliminary result for this reaction, it was performed again for a longer time, according to the literature, in the presence of triphenylphosphine. To understand the behavior of the catalyst, two solvents with different polarities based on the previous study with PdCC (Table 1, entries 13 and 14) were used. Using dioxane as solvent, no satisfactory result was obtained, achieving only $10 \%$ yield. On the other hand, when using toluene as solvent, the coupling product yield increased to $40 \%$. 
Table 2. Variation of the substrate in the reactions of Suzuki with PdCC

\begin{tabular}{|c|c|c|c|c|c|}
\hline entry & Temperature $/{ }^{\circ} \mathrm{C}$ & $\mathrm{X}$ & $\mathrm{R}$ & $\mathrm{R}^{\prime}$ & Yield $^{\mathrm{b}} / \%$ \\
\hline 1 & 30 & I & $\mathrm{H}$ & $4-\mathrm{OCH}_{3}$ & 100 \\
\hline 2 & 30 & $\mathrm{Cl}$ & $4-\mathrm{OCH}_{3}$ & $\mathrm{H}$ & 2 \\
\hline 3 & 30 & $\mathrm{Br}$ & $4-\mathrm{OCH}_{3}$ & $\mathrm{H}$ & 100 \\
\hline 4 & 30 & $\mathrm{Br}$ & $\mathrm{H}_{3} \mathrm{CC}=\mathrm{O}$ & $\mathrm{H}$ & 100 \\
\hline 5 & 30 & $\mathrm{Br}$ & 4- $\mathrm{CH}_{3}$ & $\mathrm{H}$ & 79 \\
\hline 6 & 30 & $\mathrm{Br}$ & $3-\mathrm{CH}_{3}$ & $\mathrm{H}$ & 71 \\
\hline 7 & 30 & $\mathrm{Br}$ & $2-\mathrm{CH}_{3}$ & $\mathrm{H}$ & 60 \\
\hline 8 & 80 & $\mathrm{Br}$ & $2-\mathrm{CH}_{3}$ & $\mathrm{H}$ & 100 \\
\hline 9 & 80 & $\mathrm{Br}$ & $2-\mathrm{CH}_{3}$ & $2-\mathrm{CH}_{3}$ & 22 \\
\hline 10 & 80 & $\mathrm{Br}$ & $2,4,6-\mathrm{CH}_{3}$ & $\mathrm{H}$ & 14 \\
\hline 11 & 80 & $\mathrm{Br}$ & $2,4,6-\mathrm{CH}_{3}$ & $2-\mathrm{CH}_{3}$ & 1 \\
\hline
\end{tabular}

a'Conditions of reactions: $0.5 \mathrm{mmol}$ of aryl halide, $0.7 \mathrm{mmol}$ of arylboronic acid, $1.5 \mathrm{mmol}$ of $\mathrm{K}_{2} \mathrm{CO}_{3}, 0.5 \%$ of $\mathrm{PdCC}, 3 \mathrm{~mL}$ of $\mathrm{H}_{2} \mathrm{O} / \mathrm{DMF}$ (1:1), $1 \mathrm{~h}$ of reaction under argon atmosphere; byield of GC based on aryl halide. R and R' are represented in the Scheme 1.

The observed reaction effect of the cellulose matrix was carried out under the same conditions using $\mathrm{Ni}(\mathrm{OAc})_{2}$ as catalyst (Table 1, entries 15 and 16). It was observed that virtually no reaction occurred, evidencing again the role of cellulose matrix in maintaining a high catalytic activity for the coupling reaction. The behavior of NiCC is opposite to the PdCC front of solvent polarity, probably due to the lower lability of nickel. For this case, the oxidative addition step has a higher probability of occurring with the less-coordinating solvent. The ICP analysis showed that no nickel leached from the catalyst, as occurred with palladium.

The general mechanism for the coupling reactions with $\mathrm{Pd}$ and $\mathrm{Ni}$ is shown as a simplified catalytic cycle of three steps: oxidative addition, transmetallation and reductive elimination (Scheme 3). The catalytic cycle begins in the oxidative addition of the electrophile to the metal, oxidizing the $\mathrm{M}(0)$ to $\mathrm{M}(\mathrm{II})$; this step is crucial to the speed of most of these reactions as its ligands exert enough influence for the $\mathrm{CC}$ ligand to participate in increasing the yield obtained, mainly in the reaction with nickel. In the transmetallation step, the transfer of an organic group to the metal core involved in the catalysis occurs. The final step of the catalytic cycle is the reductive elimination, where the formation of the new carbon-carbon bond and groups that are joined must be in the cis position; then, it will return to the metal oxidation state (0), thus reestablishing the catalytic cycle.

The homocoupling reactions occurs, though on a minor scale, because the additive oxidation of aryl halides in $\mathrm{Pd}$ and $\mathrm{Ni}$ cores is kinetically faster. The homocoupling mechanism is suggested to involve the entry of aryl boronic acids in the coordination sphere of the metal by insertion, mediated by a strong nucleophilic ligand such as $\mathrm{HO}^{-}$.
After another insertion of another arylboronic acid, they can homocouple by eliminative reduction.

\section{CuCC C-O bound cross coupling reactions}

The $\mathrm{CuCC}$ performance was evaluated for the reaction of bromobenzene using methanol as a reactant and solvent for $6 \mathrm{~h}$ with and without phenanthroline as ligand (Table 3, entries 1 and 2, respectively). Although the presence of the $\mathrm{CC}$ ligand gave better yields, they were very low, even after $24 \mathrm{~h}$ (Table 3, entry 3). Low yields were also obtained for the reaction of $n$-pentanol (Table 3, entries 4-9). For the long-chain alcohol, a significant amount of by-product amyl ether was observed (up to $8 \%$ ).

Due to the low activity of bromobenzene, we used iodobenzene (Table 3, entries 10 and 11). We were delighted to see that the quantitative yield of coupling product was obtained after $24 \mathrm{~h}$ (entry 11). In addition, the formation of the ether by-product was minimized $(<1 \%)$. We also ran some initial tests using $N$-benzylmethylamine in place of the alcohols. However, no formation of the $\mathrm{C}-\mathrm{N}$ coupling product was observed. More studies are needed for the use of the $\mathrm{CuCC}$ in the formation of $\mathrm{C}-\mathrm{N}$ bonds.

It is important to highlight the increased yielding obtained when using $\mathrm{Pd}, \mathrm{Ni}$ or $\mathrm{Cu}$ ions complexed with carboxyl cellulose ligand, when comparing to the standard acetates metal salts, usually used for comparison reasons in the literature. It is important to highlight that among the several classes of ligands already studied in more than 3 thousand works available in the literature this work describes for the first time the application of a cellulose derivative as ligand for Suzuki cross-coupling reactions (see for instance the very recent review of Suzuki catalysts by Maluenda and Navarro). ${ }^{48}$ 


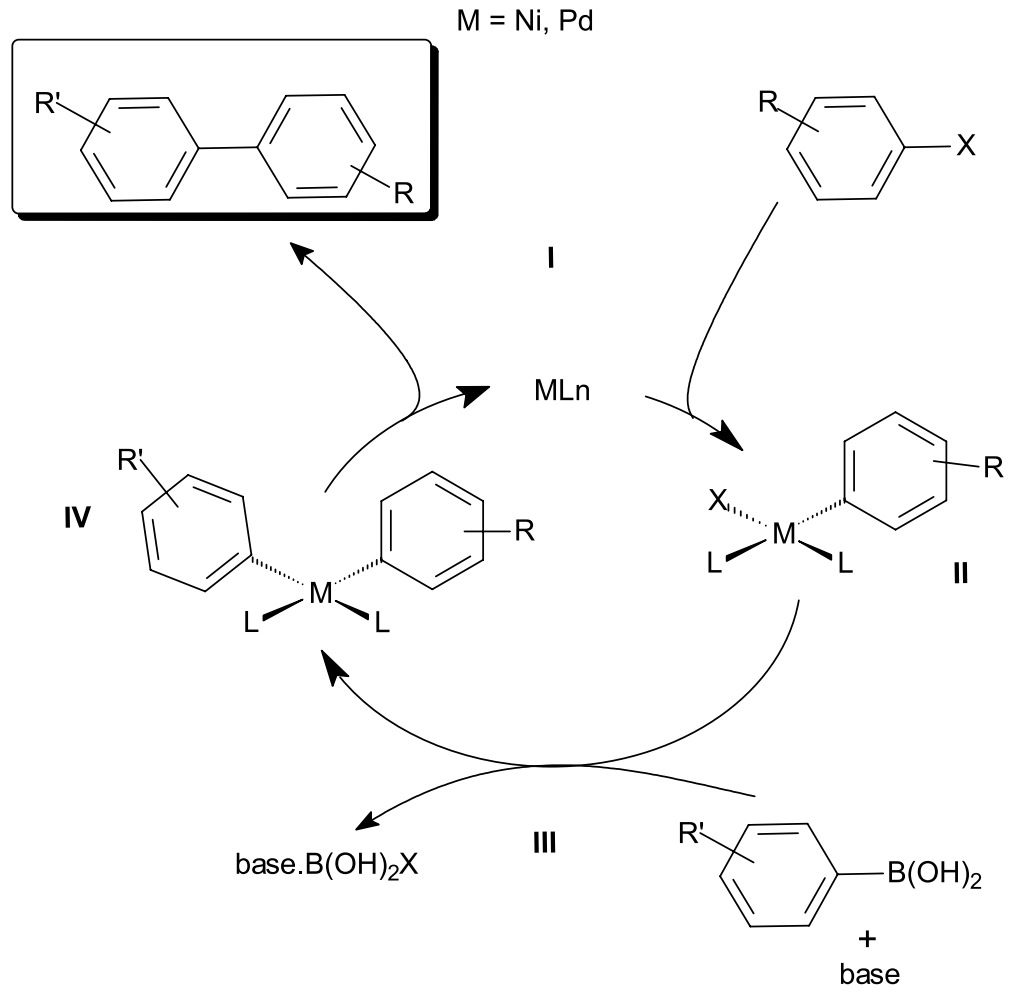

Scheme 3. Textbook proposed catalytic cycle for coupling reaction using $\mathrm{Ni}$ and $\mathrm{Pd}$ as catalyst. ${ }^{47}$

Table 3. Results for $\mathrm{C}-\mathrm{O}$ bond formation reaction promoted by $\mathrm{CuCC}^{\mathrm{a}}$

\begin{tabular}{|c|c|c|c|c|c|}
\hline entry & $\mathrm{PhX}$ & $\mathrm{ROH}$ & time $/ \mathrm{h}$ & $\mathrm{Ph}-\mathrm{OR}$ yield $/ \%$ & ROR yield / \% \\
\hline 1 & $\mathrm{PhBr}$ & $\mathrm{MeOH}$ & 6 & 6 & - \\
\hline $2^{\mathrm{b}}$ & $\mathrm{PhBr}$ & $\mathrm{MeOH}$ & 6 & 3 & - \\
\hline 3 & $\mathrm{PhBr}$ & $\mathrm{MeOH}$ & 24 & 6 & - \\
\hline 4 & $\mathrm{PhBr}$ & n-PeOH & 6 & 4 & 6 \\
\hline $5^{\mathrm{e}}$ & $\mathrm{PhBr}$ & n-PeOH & 6 & $<1$ & 6 \\
\hline 6 & $\mathrm{PhBr}$ & n-PeOH & 24 & 11 & 8 \\
\hline $7^{\mathrm{b}}$ & $\mathrm{PhBr}$ & n-PeOH & 24 & 7 & 7 \\
\hline $8^{c}$ & $\mathrm{PhBr}$ & n-PeOH & 24 & 7 & 2 \\
\hline $9^{d}$ & $\mathrm{PhBr}$ & n-PeOH & 24 & $<1$ & - \\
\hline 10 & $\mathrm{PhI}$ & n-PeOH & 6 & 81 & $<1$ \\
\hline 11 & $\mathrm{PhI}$ & n-PeOH & 24 & 100 & $<1$ \\
\hline
\end{tabular}

aReaction conditions: $1.0 \mathrm{mmol}$ of phenyl halide, $1 \mathrm{~mL}$ of alcohol, $2.0 \mathrm{mmol}$ of $\mathrm{Cs}_{2} \mathrm{CO}_{3}, 5.0 \mathrm{~mol} \%$ of phenanthroline, $1.0 \%$ of $\mathrm{CuCC}, 24 \mathrm{~h}$ at $130{ }^{\circ} \mathrm{C}$, under argon atmosphere; ${ }^{b}$ without phenanthroline; ${ }^{\mathrm{c}}$ with $\mathrm{Cu}(\mathrm{OAc})_{2}$; ${ }^{\mathrm{d}}$ accomplished with $1.4 \mathrm{mmol}$ of 1-penthanol and $1 \mathrm{~mL}$ of toluene as solvent; ${ }^{\mathrm{e}}$ reaction accomplished at $60^{\circ} \mathrm{C}$; fyield of GC based on aryl halide; syield etherification of alcohols.

\section{Conclusions}

In summary, we report the preparation of new catalytic systems based on palladium, nickel and copper complexed in modified commercial cellulose. These new catalysts can be used for application in organic reactions involving $\mathrm{C}-\mathrm{C}$ and $\mathrm{C}-\mathrm{O}$ bond formation to obtain products of great importance for the chemical and pharmaceutical industry with a satisfactory activity under heterogeneous conditions.
The efficient and environmentally friendly methodology that was developed contributes to the advancement of sustainable chemistry adding value to cellulose. We are currently deepening our studies in the use of these new materials, as well as using other metal cations, for other reactions, such as biodiesel production and modifications, and we believe that cellulose modified ligands may be further used in several other environmental friendly catalytic systems. 


\section{Acknowledgments}

The authors are in debt to CAPES (PROCAD project No. 35/2010), INCT-Catálise, CNPq, FAPERGS, and FAPDF for partial financial support. M. R. S. thanks the CAPES for post-doctoral financial support, P. A. Z. S. and A. L. M. thanks CNPq for research fellowship.

\section{References}

1. http://iba.org/images/shared/iba_2015.pdf, accessed in March 2017.

2. Fox, S. C.; Li. B.; Xu, D.; Edgar, K. J.; Biomacromolecules 2011, 12, 1956.

3. Oliveira, F. F. D.; Santos, M. R.; Lalli, P. M.; Schmidt, E. M.; Bakuzis, P.; Lapis, A. A. M.; Monteiro, A. L.; Eberlin, M. N.; Neto, B. A. D.; J. Org. Chem. 2011, 76, 10140.

4. Santos, M. R.; Diniz, J. R.; Arouca, A. M.; Gomes, A. F.; Gozzo, F. C.; Tamborim, S. M.; Parize, A. L.; Suarez, P. A. Z.; Neto, B. A. D.; ChemSusChem 2012, 5, 716.

5. Santos, M. R.; Gomes, A. F.; Gozzo, F. C.; Suarez, P. A. Z.; Neto, B. A. D.; ChemSusChem 2012, 5, 2383.

6. Santos, M. R.; Dutra, R. C.; Godoi, M. N.; Monteiro, A. L.; Benedito, H. C.; Eberlin, M. N.; Neto, B. A. D.; New J. Chem. 2014, 38, 2958.

7. Du, Q. W.; Li, Y. Q.; Beilstein J. Org. Chem. 2011, 7, 378.

8. Jamwal, N.; Sodhi, R. K.; Gupta, P.; Paul, S.; Int. J. Biol. Macromol. 2011, 49, 930.

9. Kumbhar, A.; Jadhav, S.; Kamble, S.; Rashinkar, G.; Salunkhe, R.; Tetrahedron Lett. 2013, 54, 1331.

10. Reddy, K. R.; Kumar, N. S.; Reddy, P. S.; Sreedhar, B.; Kantam, M. L.; J. Mol. Catal. A: Chem. 2006, 252, 12.

11. Quignard, F.; Choplin, A.; Chem. Commun. 2001, 1, 21.

12. Shaterian, H. R.; Rigi, F.; Res. Chem. Intermed. 2014, 40, 2983.

13. Sun, J.; Wang, J.; Cheng, W.; Zhang, J.; Li, X.; Zhang, S.; She, Y.; Green Chem. 2012, 14, 654.

14. Dabbawala, A. A.; Sudheesh, N.; Bajaj, H. C.; Dalton Trans. 2012, 41, 2910.

15. Moro, A. V.; Santos, M. R.; Correia, C. R. D.; Eur. J. Org. Chem. 2011, 36, 7259 .

16. Corbet, J. P.; Mignani, G.; Chem. Rev. 2006, 106, 2651.

17. Cahiez, G.; Moyeux, A.; Chem. Rev. 2010, 110, 1435.

18. Jana, R.; Pathak, T. P.; Sigman, M. S.; Chem. Rev. 2011, 111, 1417.

19. Baran, T.; Açıksöz, E.; Mentes, A.; J. Mol. Catal. A: Chem. 2015, $407,47$.

20. Wang, X.; Hu, P.; Xue, F.; Wei, Y.; Carbohydr. Polym. 2014, $114,476$.

21. Kochkar, H.; Morawietz, M.; Hölderich, W. F.; Stud. Surf. Sci. Catal. 2000, 130, 545.
22. Bragd, P. L.; Besemer, A. C.; van Bekkum, H.; Carbohydr. Res. 2000, 328, 355.

23. Bragd, P. L.; Besemer, A. C.; van Bekkum, H; J. Mol. Catal. A: Chem. 2001, 170, 35.

24. Bragd, P. L.; Besemer, A. C.; van Bekkum, H.; Carbohydr. Polym. 2002, 49, 397.

25. Hirota, M.; Tamura, N.; Saito, T.; Isogai, A.; Carbohydr. Polym. 2009, 78, 330 .

26. Isobe, N.; Chen, X.; Kim, U.-J.; Kimura, S.; Wada, M.; Saito, T.; Isogai, A.; J. Hazard. Mater. 2013, 260, 195.

27. Meng, Q.; Li, H.; Fu, S.; Lucia, L. A; React. Funct. Polym. 2014, 85, 142.

28. Gholinejad, M.; Shahsavari, H. R.; Razeghi, M.; Niazi, M.; Hamed, F.; J. Organomet. Chem. 2015, 796, 3.

29. Zarei, A.; Khazdooz, L.; Hajipour, A. R.; Rafiee, F.; Azizi, G.; Abrishami, F.; Tetrahedron Lett. 2012, 53, 406.

30. Prado, A. G. S.; Quim. Nova 2003, 26, 738.

31. da Silva, F. M.; de Lacerda, P. S.; Junior, J. J.; Quim. Nova 2005, $28,103$.

32. Zim, D.; Monteiro, A. L.; Tetrahedron Lett. 2002, 43, 4009.

33. Limberger, J.; Leal, B. C.; Back, D. F.; Dupont, J.; Monteiro, A. L.; Adv. Synth. Catal. 2012, 354, 1429.

34. Yang, S. L.; Xie, W. B.; Zhou, H.; Wu, C. Q.; Yang, Y. Q.; Niu, J. J.; Yang, W.; Xu, J. W.; Tetrahedron 2013, 69, 3415.

35. Saito, T.; Kimura, S.; Nishiyama, Y.; Isogai, A.; Biomacromolecules 2007, 8, 2485.

36. Saito, T.; Isogai, A.; Biomacromolecules 2004, 5, 1983.

37. Vo, H. T.; Widyaya, V. T.; Jae, J.; Kim, H. S.; Lee, H.; Bioresour. Technol. 2014, 167, 484.

38. Van Loon, L. R.; Glaus, M. A.; J. Environ. Polym. Degr. 1997, $5,97$.

39. Brethauer, S.; Wyman, C. E.; Bioresour. Technol. 2010, 101, 4862.

40. Teixera, V. G.; Coutinho, F. M. B.; Gomes, A. S.; Quim. Nova 2001, 24, 808.

41. Suzuki, A.; Pure Appl. Chem. 1991, 63, 419.

42. Suzuki, A.; Pure Appl. Chem. 1994, 66, 213.

43. Suzuki, A.; J. Organomet. Chem. 1999, 576, 147.

44. Zim, D.; Monteiro, A. L.; Dupont, J.; Tetrahedron Lett. 2000, 41, 8199.

45. Martin, R.; Buchwald, S. L.; Acc. Chem. Res. 2008, 41, 1461.

46. Zim, D.; Lando, V. R.; Dupont, J.; Monteiro, A. L.; Org. Lett. 2001, 3, 3049.

47. Matos, K.; Soderquist, J. A.; J. Org. Chem. 1998, 63, 461.

48. Maluenda, I.; Navarro, O.; Molecules 2015, 20, 7528.

Submitted: December 10, 2016

Published online: March 14, 2017

FAPERGS/CAPES has sponsored the publication of this article. 